\title{
Reducing instruments in a vitrectomy surgical tray: cost savings and results from a major academic hospital
}

\author{
Jacob D. Grodsky ${ }^{1}$, Christos N. Theophanous², Sidney A. Schechet ${ }^{2}$, Peter B. Veldman²
}

and Seenu M. Hariprasad ${ }^{2 *}$

\begin{abstract}
Background: Unused or rarely used instruments in standard surgical trays can unnecessarily increase costs. Prior studies have demonstrated the practicality and cost savings of reduced instrument tray sizes in various subspecialties. This study describes results and estimated cost savings from a reduced instrument tray used for vitrectomy surgery at a large, tertiary academic medical center.

Methods: Common usage patterns of vitrectomy instruments by one retina surgeon were reviewed and a reduced instrument vitrectomy tray was created and implemented in successive vitrectomy surgeries. Need for opening the previously utilized larger tray was recorded. Estimated cost savings of the new trays were calculated based upon per instrument sterilization, processing, and instrument replacement costs.

Results: New vitrectomy trays including just 7 instruments (89\% reduction compared to original trays) were created and implemented in 189 successive cases. The original tray was never opened. Estimated cost savings from saved sterilization and processing resources is approximately $\$ 9588$ per year. Assuming 5 - and 10 -year lifespan per instrument, annual cost avoidance is projected at $\$ 7886$ and $\$ 15,772$, respectively. Other indirect benefits relevant to healthcare quality were also noted.

Conclusion: A reduced instrument tray can be successfully implemented for vitrectomy surgery and can result in significant indirect benefits as well as direct cost savings from reduced sterilization costs. Our study highlights the substantial impact made by evaluating the usage pattern and making appropriate instrument tray changes for just one retina surgeon. Applying these same methods to other surgeons and specialties can have significant implications on healthcare costs and quality.
\end{abstract}

\section{Background}

Surgical trays that contain unused instruments can lead to unnecessary costs for hospitals [1-3]. Specifically, unused instruments undergo sterilization between each case, resulting in both direct labor costs and more rapid

\footnotetext{
*Correspondence: retina@uchicago.edu

${ }^{2}$ Department of Ophthalmology and Visual Science, University

of Chicago Medicine, 5741 S. Maryland Avenue, S-439, Chicago, IL 60637, USA

Full list of author information is available at the end of the article
}

wear and tear of instruments [1, 2, 4, 5]. In addition, unpacking large trays can add to case turnover time and increase time spent counting items both before and after each case $[2,4,5]$. As a result, reducing instrument tray size by eliminating unused or rarely used instruments may represent a cost savings opportunity.

Previous studies have demonstrated that standard surgical trays often contain numerous rarely used instruments $[1,3]$. Studies also demonstrate that a reduction in main instrument tray size led to a reduction in instrument assembly time, setup time, and increased surgeon

c) The Author(s) 2020. This article is licensed under a Creative Commons Attribution 4.0 International License, which permits use, sharing, adaptation, distribution and reproduction in any medium or format, as long as you give appropriate credit to the original author(s) and the source, provide a link to the Creative Commons licence, and indicate if changes were made. The images or other third party material in this article are included in the article's Creative Commons licence, unless indicated otherwise in a credit line to the material. If material is not included in the article's Creative Commons licence and your intended use is not permitted by statutory regulation or exceeds the permitted use, you will need to obtain permission directly from the copyright holder. To view a copy of this licence, visit http://creativeco mmons.org/licenses/by/4.0/. The Creative Commons Public Domain Dedication waiver (http://creativecommons.org/publicdomain/ zero/1.0/) applies to the data made available in this article, unless otherwise stated in a credit line to the data. 
and scrub personnel satisfaction [3]. Such reductions in surgical tray instrumentation can generate cost savings, which have been estimated in several surgical specialties. For instance, a $70 \%$ instrument reduction in surgical trays used for both minimally invasive spine surgery and deep brain stimulation surgery demonstrated a cost savings of approximately $\$ 60,000$ per year [2]. A study from Canada demonstrated that reducing redundant instruments from trays for five common otolaryngology procedures saved an estimated CAD 13,000 annually [5]. Additional cost savings can be seen by avoiding instrument purchase and replacement costs through reduced surgical trays and delaying wear and tear of instruments [6].

To our knowledge, no study has used similar methodology to analyze any ophthalmic surgical trays, create and implement a reduced instrument tray, and calculate expected cost savings. A thorough review of the current

\begin{tabular}{|c|c|c|}
\hline Study & Surgical Field & $\begin{array}{l}\text { Percent Instrument } \\
\text { Reduction (\%) }\end{array}$ \\
\hline Byrnes 2017 [7] & Gynecology & 28.4 \\
\hline Chin 2014 [1] & Otolaryngology & 57 \\
\hline \multirow[t]{5}{*}{ Farrelly 2017 [6] } & Pediatric surgery & 39.5 (General) \\
\hline & & 10.1 (Urology) \\
\hline & & 17.1 (Orthopedics) \\
\hline & & 92.7 (Spine) \\
\hline & & 32.3 (Neurosurgery) \\
\hline Farrokhi 2015 [2] & $\begin{array}{l}\text { Minimally invasive } \\
\text { spinal surgery }\end{array}$ & 70 \\
\hline John-Baptiste 2016 [5] & Otolaryngology & 56.4 \\
\hline Nast 2019 [8] & Pediatric urology & 38 \\
\hline Wannemuehler 2015 [3] & Otolaryngology & 54 \\
\hline
\end{tabular}

literature has revealed studies from various other medical fields that analyzed and reduced the number of instruments in surgical trays (Table 1). In this study, we identified commonly unused instruments included in our standard vitrectomy tray and sought to create a reduced instrument tray. After creating and implementing this new tray into our surgical workflow, we then recorded the need for opening additional instruments due to inability to complete a case with the newly created reduced instrument tray. Lastly, we calculated estimated annual cost savings based on these changes.

\section{Methods}

This study designed and implemented a new reduced instrument vitrectomy tray utilized by one retina surgeon. Instruments contained in the standard vitrectomy tray were reviewed for redundancy, and those utilized in the majority of vitrectomy cases were included in the new reduced instrument tray. Images of the standard and reduced trays are shown in Figs. 1, 2.

Unnecessary instruments not frequently used in vitrectomy surgery that had been added to the standard tray over previous years were excluded from the new reduced tray (Table 2). IRB approval is not required at our institution for studies of this nature. In addition, it was not appropriate or possible to involve patients or the public in this work.

We estimated the expected cost savings of implementing the smaller trays based on internal institution costs for instrument sterilization. Utilizing the general formula published by Farrokhi et al., we estimated internal sterilization costs per instrument by dividing the total costs for 1 year of instrument sterilization for the University of Chicago Medicine Central Sterile Processing (CSP) department between July 1, 2017 and June 30, 2018 by the total number of surgical instruments sterilized in
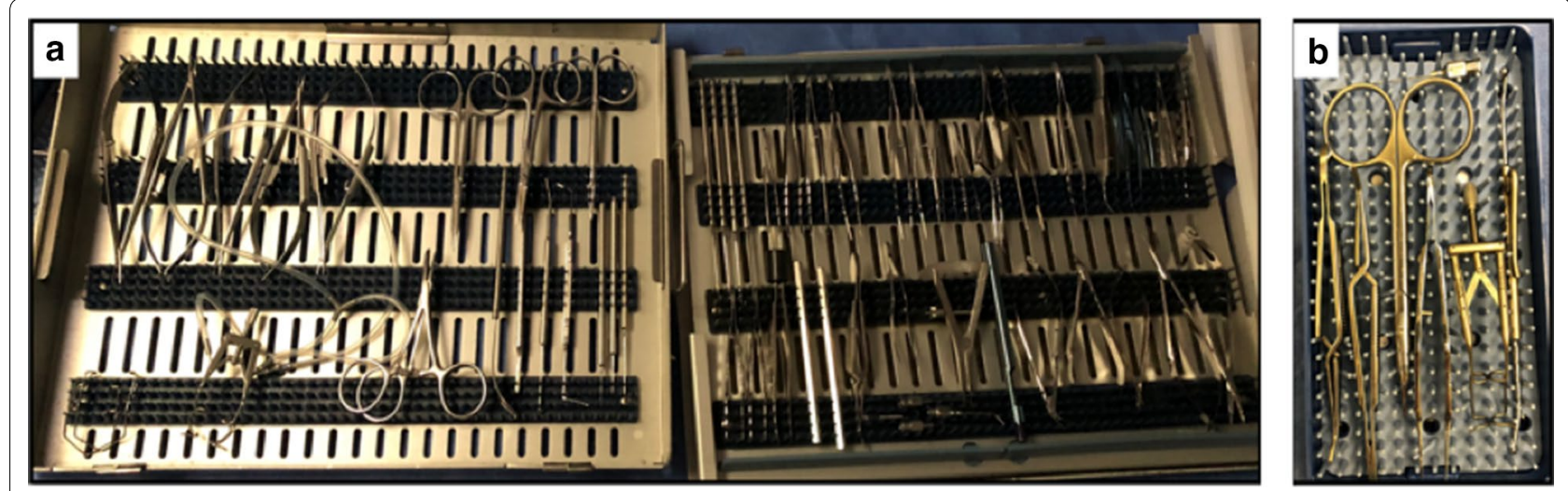

Fig. 1 a Standard vitrectomy tray containing 64 instruments; b Reduced instrument vitrectomy tray containing 7 instruments 


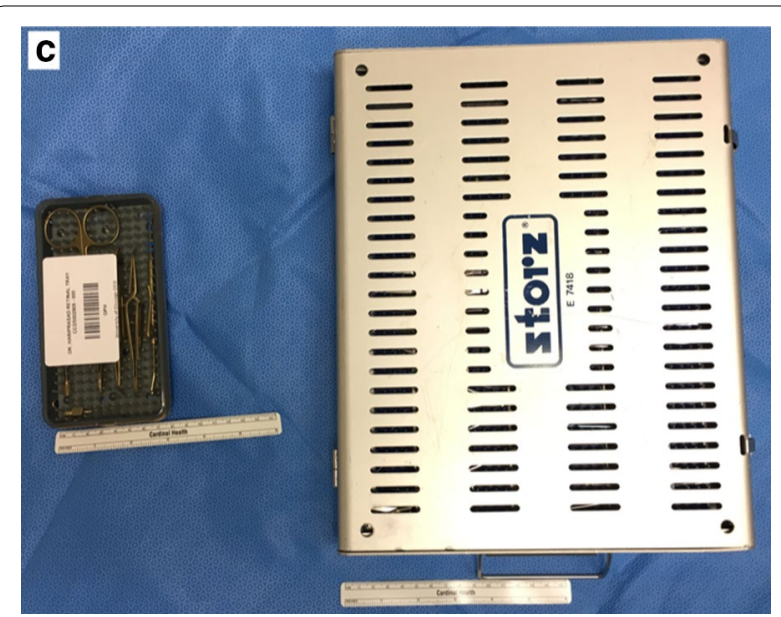

Fig. 2 c Size comparison of reduced (left) and standard (right) vitrectomy trays

that same time period [2]. The total costs reflected the entire budget of the department, including both physical resource costs, labor, instrument repair and replacement, and necessary utilities and supplies for instrument cleaning. Estimated cost savings per instrument in our reduced vitrectomy tray were annualized by multiplying the number of instruments excluded from the reduced vitrectomy trays by the total number of vitrectomy cases performed using only the new tray during a 12-month time period.

Data related to instrument cost avoidance was obtained via quotes from University of Chicago vendors. Individualized instrument costs were obtained and used to calculate annual instrument cost avoidance. Recognizing that instruments have varying life expectancies, annual instrument cost avoidance savings are based on a range of replacing instruments every 1,5 , or 10 years, consistent with previously published analyses [6].

The reduced instrument trays were implemented and opened for all vitrectomy cases performed by one retina surgeon between July 15, 2018 and July 14, 2019. During this 12 -month period, the original large vitrectomy tray was kept in circulation to be opened only if additional instrumentation was needed during cases. The number of cases requiring instruments from the larger tray during this period was recorded.

\section{Results}

The original standard vitrectomy trays included 64 instruments. Of these, 7 instruments were used in a majority of cases and were included in the reduced trays, resulting in an $89 \%$ reduction of instruments. Reduced trays measured $8.4 \mathrm{~cm} \times 15.8 \mathrm{~cm}$ and weighed $0.22 \mathrm{~kg}$ compared to standard trays that measured $25.8 \mathrm{~cm} \times 33.0 \mathrm{~cm}$ and weighed $3.0 \mathrm{~kg}$ ( $84 \%$ reduction by surface area on scrub table and $93 \%$ reduction by weight).

During our study duration, we had 189 successive vitrectomy cases. Indications for vitrectomy and surgical procedures performed are shown in Table 3.

During these 189 cases, the reduced instrument tray was used for the entire case in all 189 cases, and the large original instrument tray was opened in zero cases.

In the 12 months preceding the study, the CSP department sterilized a total of 5,254,400 instruments. During that time, total costs for the CSP department were $\$ 5,886,465.50$. Instrument sterilization cost was calculated to be $\$ 0.89$ per instrument [2]. As the reduced instrumentation tray excluded 57 previously included instruments, each vitrectomy case utilizing only the reduced instrument tray resulted in an estimated cost savings of $\$ 50.73$. With these estimates, the total annual cost savings of the new vitrectomy sets in 189 cases is approximately $\$ 9588$.

Using data obtained from our institution's preferred instrument supplier, the 57 instruments eliminated from the reduced instrument tray cost $\$ 9857$ to replace. Our institution currently has 8 of our original vitrectomy trays as well as 8 of our new mini vitrectomy trays in circulation. By eliminating 57 instruments from each of our original trays, this results in a projected annual cost avoidance of $\$ 7886$ and $\$ 15,772$ in replaced vitrectomy instruments, assuming a 10-year or 5-year instrument lifespan, respectively.

\section{Discussion}

This study demonstrates that a reduced instrument tray can be successfully implemented for vitrectomy surgeries and result in significant estimated cost savings. We achieved an $89 \%$ reduction in instruments included in the standard vitrectomy kit when creating our new kit. Opening the larger original tray was never needed during 189 successive vitrectomy cases for a variety of indications.

Cost savings per instrument calculated in our study are roughly in line with previously published sterilization cost estimates by Farrokhi et al. [2] They are, however, higher than a study by Stockert et al. previously performed at our institution in which sterilization cost per instrument ranged from $\$ 0.12$ to $\$ 0.51$ [4]. These values were calculated through estimations and analysis of CSP labor costs, instrument depreciation, CSP department utilities, and repair costs. Elements of their methodology have been cited by several other studies [5]. Since the study was performed, the CSP department sterilizes approximately $57 \%$ more instruments per year and granular data on the elements included in the study could not 
Table 2 Instruments included in standard and reduced instrument vitrectomy trays

\begin{tabular}{|c|c|c|c|}
\hline \multicolumn{2}{|l|}{ Standard large vitrectomy tray $(n=64)$} & \multicolumn{2}{|l|}{ Newly created reduced vitrectomy tray $(n=7)$} \\
\hline Instrument & Quantity & Instrument & Quantity \\
\hline Westcott tenotomy scissor, curved blunt & 2 & Lieberman, open wire, angled, 45-degree speculum & 1 \\
\hline Vannas scissors, curved & 1 & Scleral depressor & 1 \\
\hline Corneal scissors, left & 1 & Castroviejo suturing forceps 0.3 & 1 \\
\hline Corneal scissors, right & 1 & Straight stevens scissors & 1 \\
\hline Plug holder & 4 & 25 G aspirating canula & 1 \\
\hline 19G cannula BSS & 2 & Plug holder & 2 \\
\hline Castroviejo caliper, straight & 1 & & \\
\hline Scleral depressor & 1 & & \\
\hline Beaver knife handle & 2 & & \\
\hline Bipolar cautery forceps & 1 & & \\
\hline Bishop harmon forceps with teeth & 2 & & \\
\hline Bishop harmon forceps without teeth & 2 & & \\
\hline Titanium tyer, short & 1 & & \\
\hline Titanium tyer, long & 1 & & \\
\hline Tyer, harms & 2 & & \\
\hline Bonaccolto forceps & 2 & & \\
\hline Colibri forceps & 1 & & \\
\hline Cross action forceps & 1 & & \\
\hline Bonn suturing forceps & 2 & & \\
\hline Castroviejo fine suturing forceps 0.12 & 2 & & \\
\hline Castroviejo suturing forceps 0.3 & 2 & & \\
\hline Nugent forceps & 2 & & \\
\hline Retaining nut for blackflush & 1 & & \\
\hline Gass retinal hook with hole & 4 & & \\
\hline Muscle hook & 1 & & \\
\hline Sinskey hook & 1 & & \\
\hline Kuglen hook & 1 & & \\
\hline Cyclodialysis spatula & 1 & & \\
\hline Scleral marker & 1 & & \\
\hline Knife handle \#3, 5" & 1 & & \\
\hline Short schepens orbital retractor & 1 & & \\
\hline Hemostat & 2 & & \\
\hline Curved stevens tenotomy scissors & 1 & & \\
\hline Straight stevens scissors & 1 & & \\
\hline Straight, sharp stevens scissors & 1 & & \\
\hline Iris scissors & 1 & & \\
\hline Wire speculum & 2 & & \\
\hline $\begin{array}{l}\text { Straight, locking, micro Barraquer needle- } \\
\text { holder }\end{array}$ & 2 & & \\
\hline Non-locking, micro Barraquer needleholder & 1 & & \\
\hline Locking needleholder & 2 & & \\
\hline $\begin{array}{l}\text { Lieberman, open wire, angled, 45-degree } \\
\text { speculum }\end{array}$ & 1 & & \\
\hline 25 G blunt canula & 1 & & \\
\hline $\begin{array}{l}\text { Lieberman aspirating speculum with silicone } \\
\text { tubing }\end{array}$ & 1 & & \\
\hline
\end{tabular}


Table 3 Indications and surgical procedures performed

\begin{tabular}{lllr}
\hline Primary indication for pars plana vitrectomy & Quantity & Intraoperative procedures performed & Quantity \\
\hline Tractional retinal detachment & 90 & $23 \mathrm{~g} \mathrm{PPV}$ & 183 \\
Rhegmatogenous retinal detachment & 25 & $25 \mathrm{~g} \mathrm{PPV}$ & 5 \\
Epiretinal membrane & 32 & $20 \mathrm{~g} \mathrm{PPV}$ & 1 \\
Vitreous hemorrhage ( \pm retinal hole or tear) & 14 & Membrane peel & Endolaser \\
Macular hole & 14 & Air/gas fluid exchange & 162 \\
Dislocated/retained lens fragments & 7 & C $_{3} F_{8}$ instillation & 112 \\
Silicone oil removal & 4 & Silicone oil instillation/removal & 104 \\
Uveitis with vitreous debris & 1 & Subtenon's steroid injection & 32 \\
Endophthalmitis & 2 & Retinectomy & 22 \\
& & Lensectomy & 3 \\
\end{tabular}

be obtained. Our cost estimates also include some overhead costs for the department that may not have been captured by the Stockert study, which explains the higher per instrument cost.

Aside from cost savings, further indirect benefits of reducing the size of vitrectomy trays were noted. Our surgical staff noticed a decrease in turnover time between cases, less time needed by the surgical scrub nurse to lay out and organize the instruments, and faster response time for the scrub nurse to hand over instruments requested by the surgeon during the case. Overall, there was a significant increase in subjective satisfaction by both the operating room staff and the retina surgeon after the implementation of the smaller instrument tray. Furthermore, we believe that the fewer number of instruments needed for each case decreases wear and tear on the unused instruments. Our study highlights the substantial impact made by evaluating the usage pattern and making appropriate surgical instrument tray changes for just one surgeon. Applying this same evaluation and adjustment methods to other surgeons and specialties can have significant implications on healthcare costs and quality.

A limitation of this study is that it focuses solely on one surgeon's experience in reducing the number of instruments included in one specific surgical tray. Different surgeons and institutions may vary widely in their instrument utilization patterns. Specific amounts and types of instruments included in the surgical tray before removing those that are unnecessary may also vary widely amongst institutions. Cost savings at other institutions will likely also differ from our results based on their individual sterilization processes, instrument wear and tear, and replacement processes. We were also unable to quantify the cost saving impact of factors such as the labor cost required to count, decontaminate, and pack the surgical trays as well as the depreciation of instruments, CSP washers, and sterilization machines.

\section{Conclusions}

We have demonstrated that there are significant direct and indirect benefits of reducing the number of instruments included in surgical trays. Our study highlights that these benefits extend not only to the surgeon, but also to the surgical staff and the hospital. Our study may also suggest opportunities for cost savings in other ophthalmologic subspecialties and for other types of ocular surgery through a systematic evaluation of instrument use patterns and streamlined standardized surgical trays. Based on our experience, we recommend that hospitals partner with their surgeons to assess and reduce surgical tray size in order to cut operating costs and reduce unnecessary time in the operating room.

\section{Abbreviation \\ CSP: Central Sterile Processing}

\section{Acknowledgements}

The operating room nurses and the staff in the Central Sterile Processing depart at the University of Chicago Medical Center for their assistance with this project.

\section{Authors' contributions}

$J G$ was a major contributor in designing the study, data gathering and analysis, creating the new vitrectomy tray, and writing the manuscript. CT was a major contributor in designing the study, data gathering and analysis, and writing the manuscript. SS was a major contributor in designing the study, data analysis, and writing the manuscript. PV was a major contributor in data gathering and creating the new vitrectomy tray. SH performed all of the vitrectomy surgeries and was a major contributor in designing the study, data analysis, creating the new vitrectomy tray, and writing the manuscript. All authors read and approved the final manuscript.

Funding

Not applicable. 


\section{Availability of data and materials}

The datasets used and/or analyzed during the current study are available from the corresponding author on reasonable request.

\section{Ethics approval and consent to participate}

Not applicable.

\section{Consent for publication}

Not applicable.

\section{Competing interests}

The authors declare that they have no competing interests.

\section{Author details}

${ }^{1}$ Department of Ophthalmology, Saint Louis University Eye Institute, 1755 South Grand Blvd., Saint Louis, MO 63104, USA. ${ }^{2}$ Department of Ophthalmology and Visual Science, University of Chicago Medicine, 5741 S. Maryland Avenue, S-439, Chicago, IL 60637, USA.

Received: 29 January 2020 Accepted: 21 March 2020

Published online: 18 June 2020

\section{References}

1. Chin CJ, Sowerby LJ, John-Baptiste A, Rotenberg BW. Reducing otolaryngology surgical inefficiency via assessment of tray redundancy. J Otolaryngol Head Neck Surg. 2014;43:46.
2. Farrokhi FR, Gunther M, Williams B, Blackmore CC. Application of lean methodology for improved quality and efficiency in operating room instrument availability. J Healthc Qual. 2015;37(5):277-86.

3. Wannemuehler TJ, Elghouche AN, Kokoska MS, Deig CR, Matt BH. Impact of lean on surgical instrument reduction: less is more. Laryngoscope. 2015;125(12):2810-5

4. Stockert EW, Langerman A. Assessing the magnitude and costs of intraoperative inefficiencies attributable to surgical instrument trays. J Am Coll Surg. 2014;219(4):646-55.

5. John-Baptiste A, Sowerby U, Chin CJ, Martin J, Rotenberg BW. Comparing surgical trays with redundant instruments with trays with reduced instruments: a cost analysis. C Open. 2016;4(3):E404-8.

6. Farrelly JS, Clemons C, Witkins S, Hall W, Christison-Lagay ER, Ozgediz DE, et al. Surgical tray optimization as a simple means to decrease perioperative costs. J Surg Res. 2017;220:320-6.

7. Byrnes JN, Schmitt J, Tommaso C, Occhino JA. 72: cost reduction techniques in the operating suite: Surgical tray optimization. Am J Obstet Gynecol. 2017;216(3):S616.

8. Nast K, Swords KA. Decreasing operating room costs via reduction of surgical instruments. J Pediatr Urol. 2019;15(2):153.e1-6.

\section{Publisher's Note}

Springer Nature remains neutral with regard to jurisdictional claims in published maps and institutional affiliations.
Ready to submit your research? Choose BMC and benefit from

- fast, convenient online submission

- thorough peer review by experienced researchers in your field

- rapid publication on acceptance

- support for research data, including large and complex data types

- gold Open Access which fosters wider collaboration and increased citations

- maximum visibility for your research: over 100M website views per year

At BMC, research is always in progress.

Learn more biomedcentral.com/submissions 